\title{
The Effects of Feed Bunk Competition on the Feed Sorting Behavior of Close-Up Dry Cows
}

\author{
A. Hosseinkhani, ${ }^{*}$ T. J. DeVries,$\dagger^{1}$ K. L. Proudfoot, $\ddagger$ R. Valizadeh, ${ }^{\star}$ D. M. Veira, $\S$ \\ and M. A. G. von Keyserlingk‡ \\ *Department of Animal Science, Ferdowsi University of Mashhad, 91775-1163, Iran \\ †Department of Animal and Poultry Science, University of Guelph, Kemptville Campus, 830 Prescott Street, Kemptville, Ontario, \\ KOG 1J0, Canada \\ $\ddagger$ Animal Welfare Program, The University of British Columbia, 2357 Main Mall, Vancouver, British Columbia, V6T 1Z4, Canada \\ $\S$ Agriculture and Agri-Food Canada, Pacific Agri-Food Research Centre, PO Box 1000, Agassiz, British Columbia, V0M 1A0, Canada
}

\begin{abstract}
The objectives of this research were to describe the feed sorting, feeding behavior, and feed intake of cows consuming a close-up ration and to determine if these behaviors are affected by competition for access to the feed bunk. Thirty-six dry Holstein cows, consuming a close-up total mixed ration diet, were assigned to 1 of 2 treatments: 1 ) noncompetitive (1 cow/feed bin) or 2 ) competitive ( 2 cows/feed bin). Dry matter intake, feeding behavior, and sorting behavior were monitored for each feed bin on 4 separate days during wk 2 and 3 before the anticipated calving dates of the cows. Fresh feed and orts were sampled daily from each bin and were subjected to particle size analysis. The particle size separator consisted of 3 screens (18, 9, and 1.18 $\mathrm{mm}$ ) and a bottom pan resulting in 4 fractions (long, medium, short, and fine). Sorting was calculated as the actual intake of each particle size fraction expressed as a percentage of the predicted intake of that fraction. Regardless of treatment, the cows sorted against long particles and for short and fine particles. Competition at the feed bunk had no effect on the sorting behavior, dry matter intake, or feeding time of the cows, but did dramatically increase the feeding rate of the cows. The competitively fed cows also had fewer meals per day, and tended to have larger and longer meals. Our results suggest that increased competition at the feed bunk promotes feeding behavior patterns that will likely increase the between-cow variation in composition of total mixed ration consumed.
\end{abstract}

Key words: competition, sorting, dry cow

\section{INTRODUCTION}

Cows have been shown to preferentially sort for the grain concentrate component of a TMR and discrimi-

Received September 7, 2007.

Accepted November 12, 2007.

${ }^{1}$ Corresponding author: tdevries@kemptvillec.uoguelph.ca nate against the longer forage components. This type of sorting behavior results in an increase in the fiber content of the remaining feed (Leonardi and Armentano, 2003). Sorting of the diet can lead to the cows consuming an inconsistent ration (Stone, 2004; DeVries et al., 2005). It is believed that cows that engage in sorting behavior consume increased amounts of grain concentrate and low amounts of fiber and are at increased risk for subacute ruminal acidosis (Cook et al., 2004; Stone, 2004). Similarly, sorting of the TMR can reduce the nutritive value of the TMR remaining in the feed bunk, particularly in the later hours past the time of feed delivery (DeVries et al., 2005). This may be detrimental for those cows that do not have access to feed, for instance due to competition as result of limited feed bunk space (DeVries et al., 2004; Huzzey et al., 2006), at the time immediately following fresh feed delivery. Cows that are unable to access the feed bunk at peak feeding times may not maintain adequate nutrient intake to meet their energy and essential nutrient requirements.

For prepartum dairy cows, the close-up period (typically 3 wk prior to calving) is a time of increasing nutrient requirements (NRC, 2001) and decreasing DMI (Hayirli et al., 2003). Consequently, dry cows are typically switched at this time from a forage-based diet to a close-up diet, which contains moderate levels of grain concentrate to increase available dietary energy (Rabelo et al., 2003) and help the rumen better adapt to the energy dense diet fed postpartum (NRC, 2001). Because dairy cattle have been shown to sort for grain concentrates, and because dry cows are switched from an allforage diet to one containing some grain concentrate, it could be hypothesized that following this dietary switch, dairy cattle would engage in sorting behavior while consuming the close-up diet. Moreover, given there may be high motivation to sort this diet, competition at the feed bunk may exacerbate this behavior. The first objective of this research was to describe the 
feed sorting, feeding behavior, and feed intake of cows consuming a close-up ration. The second objective was to determine if these behaviors are affected by competition for access to the feed bunk.

\section{MATERIALS AND METHODS}

\section{Animals, Housing, and Diet}

Thirty-six dry Holstein cows, 8 primiparous and 28 multiparous (parity $=2.4 \pm 1.3$; mean $\pm \mathrm{SD}$ ), were used in the study. The cows were housed in a free-stall barn located at The University of British Columbia Dairy Education and Research Center (Agassiz, British Columbia, Canada) and were managed according to the guidelines set by the Canadian Council on Animal Care (1993). Cows were housed in 2 pens at a stocking density of 9 cows per pen. Each pen contained 2 rows of 6 free stalls (mattress with sand) with 3 free stalls blocked so that each cow had access to 1 stall. Feed and water were provided ad libitum using 6 roughage and 1 water intake control feed bins per pen (Insentec B.V., Marknesse, the Netherlands).

The TMR was formulated according to the NRC (2001) nutrient requirement recommendations for close-up dairy cows (Table 1). The diet was mixed using a TMR mixer wagon and was delivered twice daily at 0800 and $2000 \mathrm{~h}$. The amount of feed offered was adjusted daily to obtain approximately $10 \%$ orts on an asfed basis. Each day, orts from the previous feeding were cleaned out of the feed bins at 0700 and $1900 \mathrm{~h}$.

\section{Experimental Design}

Once a cow reached $27 \mathrm{~d}$ before her expected calving date, the cow was moved from a far-off pen to a training pen equipped with the electronic feeding system. The design of the feeding system allowed for each cow to be assigned to an individual bin in each pen. In the training pen, cows were programmed to access feed from a single bin ( 1 cow/feed bin). On $23 \mathrm{~d}$ before their expected calving date, cows were moved to 1 of 2 prepartum pens where they were alternately assigned to 1 of 2 treatments: 1) a noncompetitive treatment in which cows had exclusive access to one bin (1 cow/feed bin) or 2 ) a competitive treatment cows in which 2 cows with similar expected calving dates shared a feed bin ( 2 cows/ feed bin). There were 9 cows in each prepartum pen at any given time, with 3 cows accessing single bins and 6 cows sharing 3 bins. The cows remained on the same treatment until they calved, at which point they were removed from the pen and were replaced by another experimental cow from the training pen.
Table 1. Ingredient and chemical composition of the TMR

\begin{tabular}{lc}
\hline Composition & \\
\hline Ingredient, \% DM $^{\text {Corn silage }}{ }^{1}$ & \\
Alfalfa hay $^{1}$ & 31.1 \\
${\text { Concentrate } \text { mash }^{2}}^{3}$ & 39.5 \\
Chemical composition & \\
DM, \% & 29.4 \\
OM, \% of DM & 49.5 \\
CP, \% of DM & 90.1 \\
ADF, \% of DM & 15.8 \\
NDF, \% of DM & 29.7 \\
NFC, \% of DM & 40.7 \\
Particle size distribution and effective fiber, & 31.2 \\
$\%$ of DM retained on sieve & \\
>19.0 mm & 18.1 \\
$<19.0,>8.0$ mm & 32.3 \\
$<8.0,>1.18$ mm & 33.4 \\
$<1.18$ mm & 16.2 \\
pef & \\
peNDF, ${ }^{4} \%$ of DM & 0.84 \\
\hline
\end{tabular}

${ }^{1}$ Corn silage: $\mathrm{DM}: 26.2 \%$, CP: $8.5 \% \mathrm{DM}, \mathrm{ADF}: 25.9 \% \mathrm{DM}, \mathrm{NDF}$ : $47.3 \%$ DM; Alfalfa hay: DM: $91.7 \%$, CP: $20.6 \%$ DM, ADF: $32.4 \%$ DM, NDF: $39.1 \%$ DM.

${ }^{2}$ Supplied by Unifeed Ltd. (Chilliwack, British Columbia, Canada), containing (on as-is basis): $60.0 \%$ ground beet pulp, $10.0 \%$ rye distillers, $8.0 \%$ canola meal, $7.0 \%$ Amipro (heat- and lignosulfonate-treated canola meal; Unifeed Ltd.), $6.0 \%$ flattened barley, 2.95\% dairy trace mineral/vitamin premix, $1.33 \%$ vitamin $\mathrm{E}, 1.0 \%$ dicalcium phosphate, $0.88 \%$ niacin, $0.75 \%$ magnesium oxide, $0.6 \%$ iodized salt, $0.59 \%$ limestone, $0.5 \%$ calcium sulfate, $0.4 \%$ cane molasses.

${ }^{3}$ Values were obtained from chemical analysis of TMR samples. $\mathrm{OM}=100-\%$ ash $. \mathrm{NFC}=100-(\% \mathrm{CP}+\% \mathrm{NDF}+\%$ fat $+\% \mathrm{ash})$.

${ }^{4}$ pef $=$ physical effectiveness factor determined as the proportion of particles retained by 3 sieves of the Penn State Particle Separator.

${ }^{5}$ peNDF $=$ measured as the NDF content of the TMR (DM basis) multiplied by the pef.

\section{Measuring Feed/Water Intake and Behavior}

The Insentec feed bins continuously measured the feeding behavior as well as individual feed intake for all experimental animals (Chapinal et al., 2007). From the recorded data, we were able to determine the duration of each visit to the feed bin, the amount of feed consumed (start weight - end weight) during each visit, and the rate of consumption for each visit. These data were then summarized to calculate daily time spent feeding $(\mathrm{min} / \mathrm{d})$, daily DMI $(\mathrm{kg} / \mathrm{d})$, and average feeding rate $(\mathrm{kg} / \mathrm{min})$.

\section{Meal Analysis}

Visits to the feed intake system were separated into meals using a meal criterion (minimum time interval that a cow is away from the feeder to be considered a meal). This meal criterion was calculated to be 16.7 min using a mixed distribution model, as outlined by DeVries et al. (2003). Using this criterion, meal frequency, duration, and size were calculated. 


\section{Feed Sampling and Analysis}

Measurements of feed particle size were done during wk 2 and 3 before the anticipated calving dates of the cows. For this, feed samples were taken on 4 random days from each bin at 0,4 , and $12 \mathrm{~h}$ after both the AM and PM feeding. Before sampling, feed in the bin was thoroughly mixed, then sampled from 3 locations in the bin and pooled. These pooled samples were mixed, divided in 2 ( 1 for particle size separation, 1 for chemical analysis), and immediately frozen. Samples for particle size separation were thawed at a later date and separated using the 3 -screen $(19,8$, and $1.18 \mathrm{~mm}$ ) Penn State Particle Separator (PSPS). This separated the particles into 4 fractions: long particles $(>19 \mathrm{~mm})$, medium particles $(<19 \mathrm{~mm},>8 \mathrm{~mm})$, short particles $(<8$ $\mathrm{mm},>1.18 \mathrm{~mm})$, and fine particles $(<1.18 \mathrm{~mm})$. Dry matter content of these and the samples for chemical analysis were determined by oven-drying at $55^{\circ} \mathrm{C}$ for $48 \mathrm{~h}$. The TMR samples for chemical analysis were ground to pass through a 1-mm screen (Brinkmann Mill, Brinkmann Instruments Co., Westbury, NY), pooled by week and shipped to Cumberland Valley Analytical Services Inc. (Maugansville, MD) for analysis of $\mathrm{DM}\left(135^{\circ} \mathrm{C}\right)$, ash $\left(535^{\circ} \mathrm{C}\right)$, ADF (AOAC, 2000), NDF (Van Soest et al., 1991), CP $(\mathrm{N} \times 6.25$; AOAC 2000; Leco FP-528 Nitrogen Analyzer, Leco, St. Joseph, MI), and fat (AOAC, 1990). Corn silage and alfalfa hay samples were taken monthly and immediately analyzed on an as-is basis by Unifeed Ltd. (Chilliwack, British Columbia, Canada) for DM, CP, ADF, and NDF using nearinfrared spectroscopy using a FOSS-NIR Systems 6500 spectrophotometer (Foss in North America, Brampton, Ontario, Canada).

\section{Calculations and Statistical Analysis}

The DMI and feeding behavior data were summarized on a feed-bin basis, that is, the data for individual cows sharing a bin in the competitive treatment were averaged to create a single value per bin. Similarly, sorting was calculated on a bin basis. Sorting was calculated as the actual DMI of each fraction of the PSPS expressed as a percentage of the predicted DMI of that fraction (Leonardi and Armentano, 2003). This was calculated for sorting that occurred during the 4-h period following feed delivery and for the entire 12-h period following feed delivery. The predicted intake for each individual fraction was calculated as the product of the DM intake of the total diet multiplied by the DM percentage of that fraction in the fed TMR. Values equal to $100 \%$ indicate no sorting, $<100 \%$ indicate selective refusals (sorting against), and $>100 \%$ indicate preferential consumption (sorting for).
For all analyses, the individual feed bin was considered as the experimental unit. Preliminary analyses revealed no interaction of daily time period (a.m./p.m.), sampling day $(1,2,3$, or 4$)$, or week ( 1 or 2 ) with treatment or time after feed delivery; therefore, the data were summarized to create one observation for each bin. To test if DMI and feeding behavior differed between dietary treatments, the data were analyzed using the MIXED procedure of SAS (1999). The model included the fixed effect of treatment, the random effect of pen, and the residual error. To test whether sorting of the experimental diets occurred, sorting for each fraction of the PSPS was summarized by bin and time after feed delivery and tested for a difference from 100 using $t$ tests. Further, to test if sorting behavior differed between treatments and time after feed delivery, the data were analyzed using the MIXED procedure of SAS (1999), treating time after feed delivery as a repeated measure. The model included the fixed effects of time after feed delivery, treatment, and time after feed delivery by treatment interaction, the random effect of pen, and the residual error. Bin within treatment by pen was included in the model as the subject of the repeated statement. Heterogeneous compound symmetry was selected as the covariance structure on the basis of best fit according to Schwarz's Bayesian information criterion. Significance was declared at $P \leq 0.05$, and a trend was reported if $0.05<P \leq 0.15$.

\section{RESULTS}

\section{Sorting}

The data for sorting at 4 and $12 \mathrm{~h}$ after feed delivery for cows fed noncompetitively and competitively are presented in Table 2. Cows sorted against long particles, regardless of treatment, at $4(P<0.01)$ and $12(P$ $<0.001) \mathrm{h}$ after feed delivery. There was no difference between the treatments, at 4 or $12 \mathrm{~h}$ after feed delivery, on the degree of sorting against long particles. An interaction revealed that competition tended to influence the sorting of medium particles differently at 4 and 12 $\mathrm{h}$ after feed delivery. At $4 \mathrm{~h}$ after feed delivery, cows sorted against medium particles when fed noncompetitively $(P=0.04)$, but did not sort for or against medium particles when fed competitively $(P=0.6)$ At $12 \mathrm{~h}$ after feed delivery, cows did not sort for or against medium particles when fed noncompetitively $(P=0.9)$, but did not sort for medium particles when fed competitively $(P=0.03)$. Regardless of treatment, cows sorted for short particles at $4(P=0.02)$ and $12(P<0.001) \mathrm{h}$ after feed delivery, and there was a tendency for more sorting for short particles at $4 \mathrm{~h}$ after feed delivery compared with at $12 \mathrm{~h}$ after feed delivery. Cows sorted for fine particles irrespective of whether they were fed noncom- 
Table 2. Effects of competition (C) on the sorting (\%) of long, medium, short, and fine particles at different times after feed delivery $(\mathrm{T})^{1}$

\begin{tabular}{|c|c|c|c|c|c|c|c|c|c|}
\hline \multirow[b]{3}{*}{ Particle size ${ }^{2}$} & \multicolumn{4}{|c|}{ Time after feed delivery } & & & & & \\
\hline & \multicolumn{2}{|c|}{$4 \mathrm{~h}$} & \multicolumn{2}{|c|}{$12 \mathrm{~h}$} & \multicolumn{2}{|c|}{ SEM } & \multicolumn{3}{|c|}{ Effect } \\
\hline & $\mathrm{NON}^{3}$ & $\mathrm{COMP}^{4}$ & $\mathrm{NON}^{3}$ & $\mathrm{COMP}^{4}$ & $4 \mathrm{~h}$ & $12 \mathrm{~h}$ & $\mathrm{~T}$ & $\mathrm{C}$ & $\mathrm{T} \times \mathrm{C}$ \\
\hline Long & 83.7 & 80.7 & 85.2 & 86.9 & 5.5 & 2.4 & 0.2 & 0.9 & 0.4 \\
\hline Medium & 97.4 & 100.6 & 100.0 & 100.6 & 1.2 & 0.3 & 0.1 & 0.05 & 0.1 \\
\hline Short & 105.7 & 105.7 & 104.1 & 103.9 & 2.2 & 0.8 & 0.15 & 0.9 & 0.9 \\
\hline Fine & 104.9 & 107.4 & 105.0 & 104.8 & 2.4 & 0.8 & 0.4 & 0.6 & 0.4 \\
\hline
\end{tabular}

${ }^{1}$ Sorting $\%=100 \times($ particle size $\mathrm{n}$ intake/particle size $\mathrm{N}$ predicted intake). Data are averaged over $4 \mathrm{~d}$ for 12 feed bins on each treatment.

${ }^{2}$ Particle size determined by Penn State Particle Separator: long $=>19 \mathrm{~mm}$, medium $=<19,>8 \mathrm{~mm}$, short $=<8,>1.18 \mathrm{~mm}$ and fine $=<1.18 \mathrm{~mm}$.

${ }^{3} \mathrm{NON}=$ noncompetitive: $1 \mathrm{cow} / \mathrm{feed}$ bin.

${ }^{4} \mathrm{COMP}=$ competitive: 2 cows/feed bin.

petitively or competitively, at $4(P=0.06, P=0.006$, respectively) and $12(P<0.001) \mathrm{h}$ after feed delivery. There was no difference between the treatments at 4 or $12 \mathrm{~h}$ after feed delivery on the degree of sorting for fine particles.

\section{Feed Intake and Behavior}

There was no difference in DMI or daily feeding time between those cows fed noncompetitively compared with those fed competitively (Table 3). Despite this, those fed competitively had a greater rate of intake compared with the cows fed noncompetitively. The hourly DMI was higher for the cows fed noncompetitively during time around feed delivery, but was consistently greater throughout the rest of the day for the competitively fed cows (Figure 1a). Similar patterns were observed for hourly feeding time (Figure 1b). The cows fed competitively consumed their feed at a much greater feeding rate throughout the day, particularly during periods of peak feeding activity (Figure 1c). The cows fed competitively had fewer meals per day; these meals, however, tended to be longer in length and larger in size (Table 3). There was no difference in total daily meal time between the 2 treatments.

\section{DISCUSSION}

During the prepartum transition period, dry dairy cows are typically switched from a forage-based diet to a close-up diet containing forage and moderate levels of grain concentrate. In the present study, the dry cows were fed a typical close-up diet containing $29.4 \%$ grain concentrate. The sorting results clearly indicate that, regardless of treatment, sorting of the feed did occur and supported our initial hypothesis. Similar to previous findings (e.g., Leonardi and Armentano, 2003; DeVries et al., 2005, 2007), cows were clearly sorting against the longest particles, and were sorting for the smallest particles. Considering the ingredients used in this ration, it is apparent that the cows were primarily sorting against the long hay and silage particles and for the grain concentrate mash, which made up the majority of the small (short and fine) particle fractions. This finding is not surprising given that increasing the grain concentrate proportion within a TMR has been shown to increase sorting against long particles, and hence NDF and peNDF, and increase sorting for shorter particles (DeVries et al., 2007). Interestingly, the cows in the present study selected more against long particles and for smaller particles than cows fed a $37.7 \%$

Table 3. Intake and feeding behavior measures for cows fed noncompetitively and competitively ${ }^{1}$

\begin{tabular}{lcccc}
\hline Item & Noncompetitive $^{2}$ & Competitive $^{2}$ & $\mathrm{SE}$ & $P$-value \\
\hline DMI, kg/d & 16.1 & 15.5 & 0.9 & 0.6 \\
Feeding time, min/d & 205.2 & 185.7 & 10.5 & 0.2 \\
Feeding rate, kg/min & 0.08 & 0.12 & 0.008 & 0.02 \\
Meal frequency, \#/d & 9.95 & 8.29 & 0.55 & 0.04 \\
Meal duration, min/meal & 27.8 & 32.6 & 1.8 & 0.08 \\
Meal size, kg/meal & 1.71 & 1.97 & 0.11 & 0.1 \\
Total daily meal time, min/d & 261.4 & 256.7 & 11.7 & 0.8 \\
\hline
\end{tabular}

${ }^{1}$ Data are averaged per animal over $4 \mathrm{~d}$ for 12 feed bins on each treatment.

${ }^{2}$ Noncompetitive: 1 cow/feed bin; competitive: 2 cows/feed bin. 

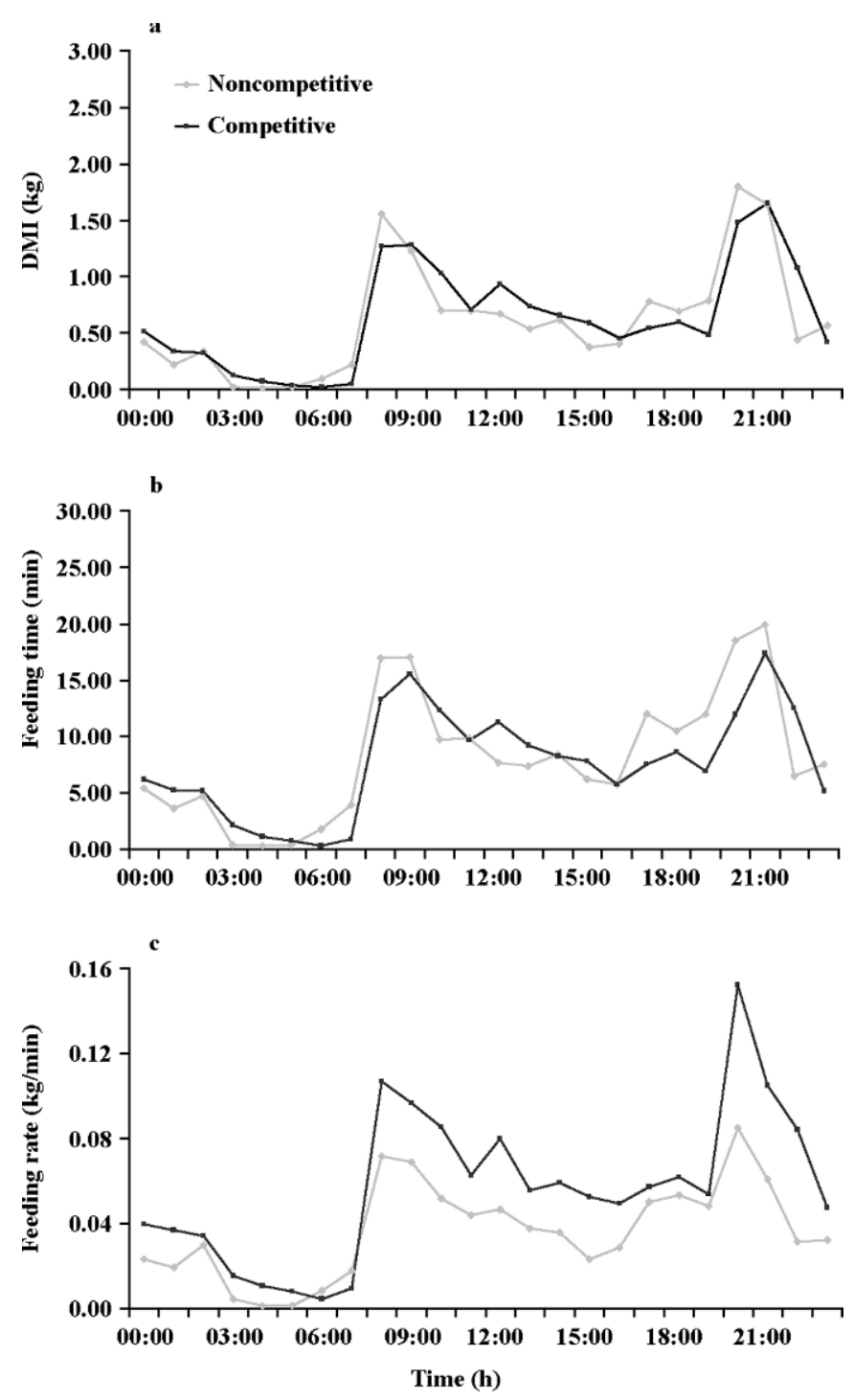

Figure 1. Hourly averages per cow for a) DMI (kg) b) feeding time ( $\mathrm{min})$, and c) feeding rate $(\mathrm{kg} / \mathrm{min})$ for cows fed noncompetitively (1 cow/feed bin) or competitively (2 cows/feed bin). Data are averaged per animal over $4 \mathrm{~d}$ for 12 feed bins on each treatment.

grain concentrate diet using the same feeding system in the DeVries et al. (2007) study. This difference could be explained by various factors, including difference in diet palatability and the close-up diet having higher dietary DM (Leonardi et al., 2005), dry hay, and a greater proportion of short particles. It is also possible that the close-up cows in this study were more motivated to sort for the smaller particles, possibly in an attempt to meet their increasing energy requirements. Regardless of the reason, such sorting behavior observed in these close-up cows may become problematic if continued into early lactation. Upon calving, the cows are commonly switched to a new diet with a much higher proportion of grain concentrate. Given that DMI increases in the weeks following calving (Kertz et al., 1991) and that increased sorting occurs on a high grain concentrate diet (DeVries et al., 2007), these will likely exacerbate the intake of short particles and refusal of long particles, NDF, and peNDF for early lactation cows. This may result in increased volatile fatty acid production, low buffering capacity, and increased risk of subacute ruminal acidosis (Cook et al., 2004; Stone, 2004).

We also hypothesized that feed bunk competition would influence the sorting behavior of cows consuming a close-up ration. For the most part, this hypothesis was refuted because there were little differences in sorting behavior between those animals fed noncompetitively compared with those fed competitively. A tendency for a treatment $\times$ time after feed delivery interaction suggested that competition may have influenced the sorting of medium particles differently at 4 and $12 \mathrm{~h}$ after feed delivery. This finding, however, is not biologically meaningful because there was minimal sorting (i.e., consumption similar to that predicted) of medium particles detected at either time for both treatments $(<3 \%$ for noncompetitive at $4 \mathrm{~h} ;<1 \%$ for noncompetitive at $12 \mathrm{~h}$; and competitive at 4 and $12 \mathrm{~h}$ ). This finding is similar to that of DeVries et al. (2007), who reported negligible sorting of medium particles for both a higher and lower concentrate diet.

The analyses of the sorting behavior also revealed minimal difference between the amounts of sorting that occurred at $4 \mathrm{~h}$ compared with $12 \mathrm{~h}$ after feed delivery, regardless of treatment. Only a weak tendency for cows to select more short particles at $4 \mathrm{~h}$ compared with $12 \mathrm{~h}$ after feed delivery was detected. Leonardi and Armentano (2003) measured sorting at $4 \mathrm{~h}$ and again at $21 \mathrm{~h}$ for individually housed cows fed once daily. These authors suggested that the 4-h data may provide interesting insight into cow behavior, but proposed that the sorting that occurs across the full day likely plays a larger role in influencing rumen function and animal performance. Although this finding may be true for individually housed animals, it may not necessarily be the case for animals fed in competitive situations. The feeding behavior data collected in this study provides evidence to suggest that within-day sorting may have a negative nutritional influence on cows that face competition for feed bunk access. Feeding cows competitively in the weeks prior to calving had no effect on daily DMI or feeding time. Interestingly, individual feed intake and feeding time were slightly lower for the cows fed competitively during time around feed delivery, but were consistently slightly higher throughout the rest of the day. On a bin level, however, this meant that much more DMI disappeared and that the feed bin was 
occupied for a much longer period of time per hour of the day, particularly during hours of peak feeding activity. As a result, to maintain similar intakes, the competitively fed cows ate $50 \%$ faster than the noncompetitively fed cows. The higher feeding rate was consistent throughout the day, particularly during periods of peak feeding activity. This is not surprising given that the motivation to feed is greatest immediately following the delivery of fresh feed (DeVries and von Keyserlingk, 2005). As assumed by Friend and Polan (1974) and demonstrated by DeVries et al. (2004), in competitive situations at the feed bunk, subordinate cows are most limited in their access to the feed bunk during times of peak feeding activity. Given that sorting for short particles occurs, combined with a tendency for more sorting in the first $4 \mathrm{~h}$ after feed delivery, cows that do not have access to feed at the time immediately following fresh feed delivery are at increased risk of consuming feed that is of reduced nutritive value. In such cases, these cows may not be able to maintain adequate nutrient intake to meet their energy and essential nutrient requirements (Krause and Oetzel, 2006).

Alternatively, the meal-based measures of feeding behavior, in conjunction with the sorting data, suggest that competition at the feed bunk could put some cows at risk for subacute ruminal acidosis. Krause and Oetzel (2006) suggested that management practices that cause adult dairy cattle to eat fewer and larger meals more quickly may be associated with an increased incidence of subacute ruminal acidosis. In the present study, the competitively fed cows had fewer meals per day, but maintained similar DMI, resulting in a tendency for these cows to have larger meals of longer duration. Ruminal $\mathrm{pH}$ declines following meals and the rate of $\mathrm{pH}$ decline increases as meal size increases and as dietary NDF concentration decreases (Allen, 1997). Therefore, the large and long meals with increased sorting of highly fermentable carbohydrates (short particles), especially in the hours after feed delivery, combined with sorting against effective fiber (long particles), would contribute to development of subacute ruminal acidosis. As suggested by Krause and Oetzel (2006), this result would be particularly evident in dominant cows, which have been shown to have priority access to feed in competitive situations at the feed bunk (DeVries et al., 2004). To improve access to feed for all animals, particularly during periods of peak feeding activity, feed bunk management strategies, including additional space or use of feed stalls, can be implemented (DeVries et al., 2004; DeVries and von Keyserlingk, 2006; Huzzey et al., 2006).

This experiment was performed with close-up dry cows whose DMI and nutrient requirements are relatively low compared with lactating cows. Early lactation cows, with increasing DMI and nutrient demands, may be more motivated to compete for feed access and to selectively sort their diets. In such situations, high competition at the feed bunk may have a more severe effect on dominant and submissive cows who may suffer nutrient overload (subacute ruminal acidosis) and deficiency, respectively. As result, cows on both ends of the social scale would likely become thin and produce poorly (Krause and Oetzel, 2006). As this is speculative, further research is needed to establish how competition influences the sorting behavior, health, and production of early lactation cows.

\section{CONCLUSIONS}

Regardless of treatment, the dry cows sorted against long particles and for short and fine particles when fed a close-up diet. Competition at the feed bunk had no effect on the feed sorting behavior of these cows. Despite this, the competitively fed cows had increased feeding rates, had fewer meals per day, and tended to have larger and longer meals. Our results suggest that increased competition at the feed bunk promotes feeding behavior patterns that will likely increase the betweencow variation in composition of TMR consumed. To prevent this, we recommend the implementation of feed bunk management strategies, including additional space or use of feed stalls, to reduce competition at the feed bunk.

\section{ACKNOWLEDGMENTS}

We thank the staff and students at The University of British Columbia's Dairy Education and Research Centre and the University's Animal Welfare Program. In particular we thank Audrey Nadalin for her technical help. The project was funded through joint contributions from the Westgen Endowment Fund and Investment Agriculture Foundation of British Columbia. General funding for the Animal Welfare Program is made available from NSERC, through the Industrial Research Chair in Animal Welfare, and contributions from the Dairy Farmers of Canada, the British Columbia Dairy Foundation, the British Columbia SPCA, members of the British Columbia Veterinary Medical Association, and many other donors listed on the Animal Welfare Web site (http://www.landfood.ubc.ca/animalwelfare).

\section{REFERENCES}

Allen, M. S. 1997. Relationship between fermentation acid production in the rumen and the requirement for physically effective fiber. J. Dairy Sci. 80:1447-1462.

AOAC. 1990. Official Methods of Analysis. 15th ed. Association of Official Analytical Chemists International, Arlington, VA. 
AOAC. 2000. Official Methods of Analysis. 17th ed. Association of Official Analytical Chemists International, Arlington, VA.

Canadian Council on Animal Care. 1993. Guide to the care and use of experimental animals. Vol. 1. E. D. Olfert, B. M. Cross, and A. A. McWilliam, ed. CCAC, Ottawa, Canada.

Chapinal, N., D. M. Veira, D. M. Weary, and M. A. G. von Keyserlingk. 2007. Validation of a system for monitoring individual feeding and drinking behavior and intake in group housed cattle. J. Dairy Sci. 90:5732-5736.

Cook, N. B., K. V. Nordlund, and G. R. Oetzel. 2004. Environmental influences on claw horn lesions associated with laminitis and subacute ruminal acidosis in dairy cows. J. Dairy Sci. 87(E. Suppl.):E36-E46.

DeVries, T. J., K. A. Beauchemin, and M. A. G. von Keyserlingk. 2007. Dietary forage concentration affects the feed sorting behavior of lactating dairy cows. J. Dairy Sci. 90:5572-5579.

DeVries, T. J., and M. A. G. von Keyserlingk. 2005. Time of feed delivery affects the feeding and lying patterns of daiy cows. J. Dairy Sci. 88:625-631.

DeVries, T. J., and M. A. G. von Keyserlingk. 2006. Feed stalls affect the social and feeding behavior of lactating dairy cows. J. Dairy Sci. 89:3522-3531.

DeVries, T. J., M. A. G. von Keyserlingk, and K. A. Beauchemin. 2005. Frequency of feed delivery affects the behavior of lactating dairy cows. J. Dairy Sci. 88:3553-3562.

DeVries, T. J., M. A. G. von Keyserlingk, and D. M. Weary. 2004. Effect of feeding space on the inter-cow distance, aggression, and feeding behavior of free-stall housed lactating dairy cows. J. Dairy Sci. 87:1432-1438.

DeVries, T. J., M. A. G. von Keyserlingk, D. M. Weary, and K. A Beauchemin. 2003. Measuring the feeding behavior of lactating dairy cows in early to peak lactation. J. Dairy Sci. 86:3354-3361.

Friend, T. H., and C. E. Polan. 1974. Social rank, feeding behavior, and free stall utilization by dairy cattle. J. Dairy Sci. 57:12141220.
Hayirli, A., R. R. Grummer, E. V. Nordheim, and P. M. Crump. 2003. Models for predicting dry matter intake of Holsteins during the prefresh transition period. J. Dairy Sci. 86:1771-1779.

Huzzey, J. M., T. J. DeVries, P. Valois, and M. A. G. von Keyserlingk. 2006. Stocking density and feed barrier design affect the feeding and social behavior of dairy cattle. J. Dairy Sci. 89:126-133.

Kertz, A. F., L. F. Reutzel, and G. M. Thomson. 1991. Dry matter intake from parturition to midlactation. J. Dairy Sci. 74:22902295 .

Krause, K. M., and G. Oetzel. 2006. Understanding and preventing subacute ruminal acidosis in dairy herds: A review. Anim. Feed Sci. Technol. 126:215-236.

Leonardi, C., and L. E. Armentano. 2003. Effect of quantity, quality, and length of alfalfa hay on selective consumption by dairy cows. J. Dairy Sci. 86:557-564.

Leonardi, C., F. Giannico, and L. E. Armentano. 2005. Effect of water addition on selective consumption (sorting) of dry diets by dairy cattle. J. Dairy Sci. 88:1043-1049.

National Research Council. 2001. Nutrient requirements for dairy cattle. Natl. Acad. Sci. Washington, DC.

Rabelo, E., R. L. Rezende, S. J. Bertics, and R. R. Grummer. 2003. Effects of pre- and postfresh transition diets varying in dietary energy density on metabolic status of periparturient dairy cows. J. Dairy Sci. 88:4375-4383.

SAS Institute Inc. 1999. SAS Users Guide. SAS Institute Inc., Cary, NC.

Stone, W. C. 2004. Nutritional approaches to minimize subacute ruminal acidosis and laminitis in dairy cattle. J. Dairy Sci. 87:E13-E26.

Van Soest, P. J., J. B. Robertson, and B. A. Lewis. 1991. Methods for dietary fiber, neutral detergent fiber and non-starch polysaccharide in relation to animal nutrition. J. Dairy Sci. 74:35833597. 